Hum. Genet. 54, 107-110 (1980)

\title{
Detection of Laser-UV Microirradiation-induced DNA Photolesions by Immunofluorescent Staining
}

\author{
C. Cremer ${ }^{1}$, T. Cremer ${ }^{2}$, M. Fukuda ${ }^{3}$, and K. Nakanishi ${ }^{3}$ \\ ${ }^{1}$ Institut für Humangenetik und Anthropologie, Universität Freiburg, Albertstr. 11, D-7800 Freiburg i. Br., \\ Federal Republic of Germany \\ ${ }^{2}$ Institut für Anthropologie und Humangenetik, Universität Heidelberg, Im Neuenheimer Feld 328, D-6900 Heidelberg, \\ Federal Republic of Germany \\ ${ }^{3}$ Department of Pathology, Kyoto Prefectural University of Medicine, Kawaramachi Hirokoji Kamikyoku, Kyoto 602, Japan
}

\begin{abstract}
Summary. A low-power laser-UV microbeam of wavelength $257 \mathrm{~nm}$ was used for microirradiation of a small part of the nucleus of Chinese hamster cells. Following fixation in interphase or in the subsequent metaphase indirect immunofluorescent staining was performed with antiserum to photoproducts of DNA treated with far UV light.

The results show that antibodies specific for UVirradiated DNA can be used for a direct detection of laser-UV microirradiation-induced DNA photolesions. The potential usefulness of this method for investigation of the spatial arrangement of chromosomes in the interphase nucleus is discussed.
\end{abstract}

\section{Introduction}

Currently available methods of detecting the distribution of DNA photolesions induced by UV microirradiation in mammalian cells (Moreno, 1971; T. Cremer et al., 1979; Zorn et al., 1979) make use of unscheduled DNA synthesis (UDS).

This technique, however, allows only detection of the sites of excision repair, and not of the DNA photolesions themselves. In this contribution a new approach is described, which allows direct demonstration of DNA photolesions in individual UV-microirradiated cells by use of antibodies specific to UV-irradiated DNA (Levine et al., 1966; Fukuda et al., 1976). Such antibodies have been used to study the potency of excision repair in single cells following whole-cell

Offprint requests to: C. Cremer or T. Cremer irradiation (Lucas, 1972; Fukuda et al., 1976; Cornelis et al., 1977).

\section{Material and Methods}

Laser-UV Microbeam

A laser-UV microbeam of wavelength $257 \mathrm{~nm}$ was used, as described in detail elsewhere (Cremer et al., 1974, 1976). Briefly, a coherent UV beam of wavelength $257 \mathrm{~nm}$, obtained by frequency doubling of an argon ion laser beam of wavelength $514 \mathrm{~nm}$, is focused into the object plane of the irradiation microscope by means of a quartz microscope objective. Here, we used a Zeiss Ultrafluar $32 \times / 0.40 \mathrm{Ph}$ Glyz giving a minimum spot diameter of approx. $1 \mu \mathrm{m}$. The irradiation objective is used simultaneously for observation of the target cells in phase contrast. Aiming is performed by means of cross-hairs in the ocular.

\section{Cell Material}

Fibroblastoid Chinese hamster cells (CHL) were obtained from lung tissue of a 3-week-old animal and grown under standard conditions (Zorn et al., 1976). Cells of passages 10-15 were used for experiments. In some cases experiments were performed with a V79 subline of the Chinese hamster (Cremer et al., 1976).

\section{Preparation of Antiserum to UV-irradiated DNA}

Antibodies to UV-irradiated DNA (mainly pyrimidine dimers) were prepared as described previousty (Fukuda et al., 1976). Briefly, denatured calf thymus DNA was irradiated with UV light of wavelength $254 \mathrm{~nm}$ and complexed with methylated bovine serum albumin (MBSA). The DNA-MBSA complex was used as an antigen to produce antibodies in rabbits. Immunodiffusion reactions showed that the antibodies produced in this way bind specifically to UV-irradiated DNA. 


\section{Irradiation and Fixation}

CHL cells synchronized by mitotic selection or asynchronously growing cells were inoculated onto glass slides in petri dishes. Before the inoculation, a number of squares were marked on the glass slides by means of a diamond pencil. Cells situated in these squares ('experimental field') were selected for microirradiation. The cells outside the experimental field were not irradiated and served as controls. In this way it was possible to relocate irradiated and unirradiated cells.

For microirradiation, the petri dishes containing the glass slides with the inoculated cells were transferred to a special irradiation chamber (Cremer et al., 1976). Then the cells were subjected to laser-UV microirradiation at a small part of the nucleus.

Following microirradiation two schedules were used: In Schedule I the cells were fixed with methanol immediately after irradiation; in Schedule II, the cells were grown for 6-19 h, and an in situ chromosome preparation (Zorn et al., 1976) was made.

In some cases, whole-cell irradiation was performed by means of a germicidal lamp emitting essentially UV light of wavelength $254 \mathrm{~nm}$. These cells were fixed according to Schedule I.

\section{Immunofluorescent Staining}

After fixation (Schedule I, II), cells were first incubated with antiserum, washed with phosphate-buffer saline, and conjugated with fluoresceinisothiocyanate (FITC)-labeled anti-rabbit immunoglobulin antibodies (indirect immunofluorescent technique).

\section{Results}

Fig. 1 shows a result of antibody staining in CHL cells fixed immediately following microirradiation (Schedule I). Small dots of strong fluorescence were detected in the nuclei of microirradiated cells. The fluorescence was localized to a small part of the nucleus. The strength of this localized fluorescence increased with incident UV energy.

No fluorescence above background was observed in unirradiated control cells. Furthermore, this type of localized fluorescence was not detected in cells exposed to whole-cell UV irradiation. We conclude that the localized fluorescence is due to binding of antibodies to DNA photolesions produced by the laser-UV microirradiation in a small part of the nucleus. The sensitivity of the antibody technique allowed detection of localized fluorescence at an incident UV energy as low as $0.3 \mathrm{~nJ}$, this energy being compatible with cell proliferation (Cremer et al., 1976).

In Fig. 2a an antibody-stained metaphase plate obtained from a V 79 cell microirradiated at one pole of the nucleus in the preceding interphase is shown (Schedule II). Fluorescence labeling was found to be restricted to a few chromosome segments only. Specific

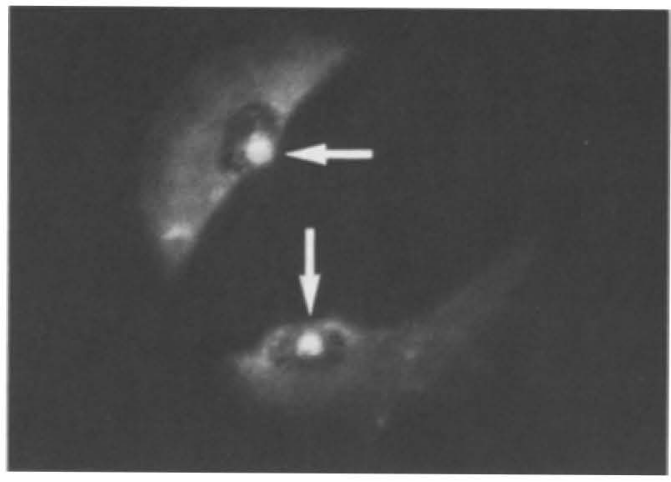

Fig. 1. Antibody staining of a CHL cell fixed immediately after laser UV microirradiation of a small part of the nucleus (incident UV energy $0.3 \mathrm{~nJ}$ ) of cells synchronized in $\mathrm{G}_{1}$. The arrows indicate the site of specific fluorescence

fluorescence was not found in metaphase plates from unirradiated cells.

The uneven distribution of antibody binding on the fluorescence-labeled chromosomes (Fig. 2b) may reflect local differences in thymidine content resulting in different amounts of thymidine dimers (Schreck et al., 1974) and/or different repair capacity along the chromosomes (Berliner et al., 1976; Johnson and Sperling, 1978).

\section{Discussion}

The results show that antibodies specific for UVirradiated DNA can be used for a direct detection of laser-UV microirradiation-induced DNA photolesions. The spot size obtained by antibody staining in Chinese hamster nuclei fixed immediately after microirradiation was found to be similar to that observed in autoradiographs of cells after microirradiation treatment in G1 and pulselabeling with ${ }^{3} \mathrm{H}$-thymidine (T. Cremer et al., 1979; Zorn et al., 1979).

Specific antibody binding was also observed following laser-UV microirradiation of the interphase nucleus of V79 cells and indirect immunofluorescent staining in the following metaphase (Fig. 2). This means that the amount of nonexcised DNA photolesions was still large enough to be detectable by antibody staining. The finding that the fluorescence labeling was restricted to a few chromosomes is in keeping with the outcome of previous experiments with CHL cells (C. Cremer et al., 1979; Zorn et al., 1979):

In these experiments, the cell nucleus was microirradiated in $\mathrm{G} 1$ and pulse-labeled with ${ }^{3} \mathrm{H}$-thymidine. UDS served as a label to follow the microirradiated chromatin from interphase to metaphase. UDS label 

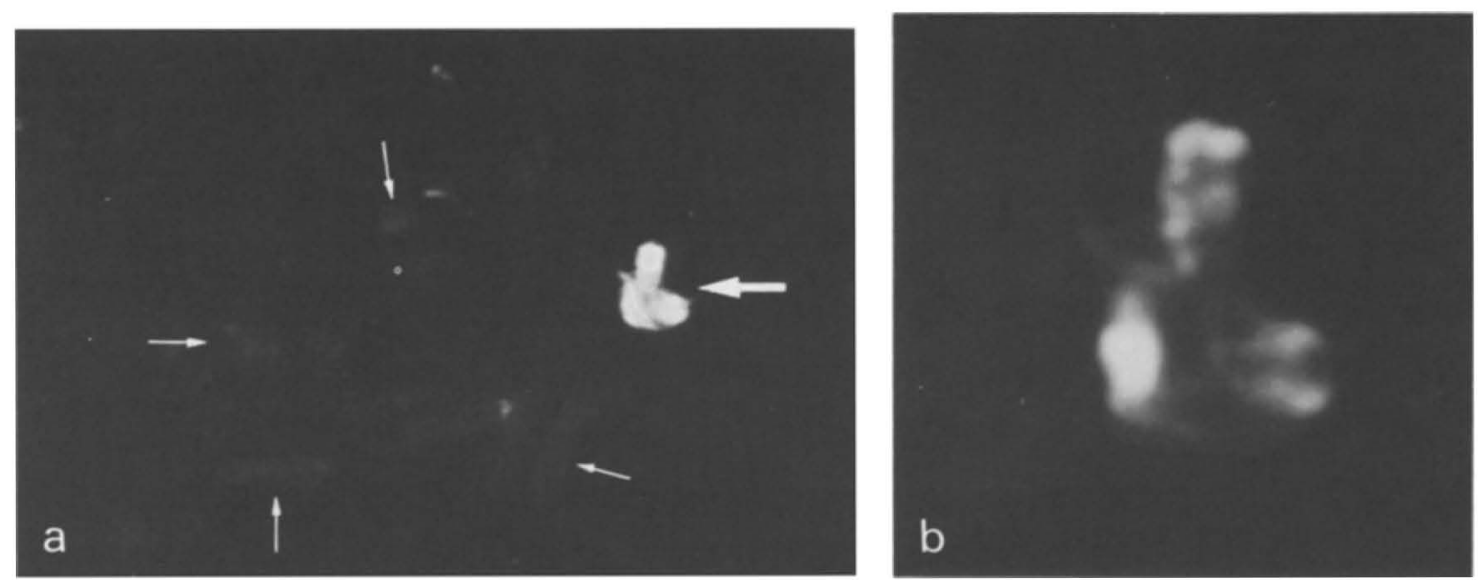

Fig. 2. a and b Microphotograph of an antibody-stained metaphase plate from a V79 cell following laser-UV microirradiation of a small part of the nucleus (incident UV energy $0.3 \mathrm{~nJ}$ ) in the preceding interphase. Chromosome preparation was performed $9 \mathrm{~h}$ after irradiation.

a Micrograph with a long exposure time: The large arrow $(\longrightarrow$ ) indicates two brightly fluorescing chromosomes lying adjacent to each other at the periphery of the metaphase plate (labeled chromosomes); the small arrows $(\rightarrow$ ) indicate unlabeled chromosomes, which are visible due to faint background fluorescence as observed in metaphase plates obtained from nonirradiated cells.

b Micrograph of the labeled chromosomes shown in a (large arrow) but with a short exposure time. Note the uneven distribution of antibody binding

was found to be concentrated to a few chromosomes lying fairly close to each other in one part of the metaphase plate.

We suggest that both methods can be used to investigate the spatial arrangement of interphase chromosomes (Comings, 1968; Vogel and Schroeder, 1974; Stack et al., 1977; Comings, 1979) according to the following experimental rationale: Cells are microirradiated at a small part of the nucleus. The microirradiated chromatin is detected in the chromosomes of the following metaphase either by unscheduled DNA synthesis or directly by antibodies specific for DNA photolesions. The labeled chromosome segments must have been situated close to each other in the preceding interphase at the time and site of irradiation.

Compared with the UDS protocol, the antibody technique has several important advantages: (1) No confusion is possible with replication patterns of semiconservative DNA synthesis; (2) all stages of the interphase cycle can be investigated; and (3) the antibody technique can be used in a wider variety of cell strains, especially in those with low levels of repair DNA synthesis (Cleaver and Trosko, 1969; Cleaver, 1974). The method can also be applied to cells of normal excision repair capacity, because even a relatively long time $(24-48 \mathrm{~h})$ after irradiation a substantial amount of dimers is retained (Cleaver et al., 1972; Amacher et al., 1977; Inoue and Takebe, 1978).

Acknowledgements. This work was supported by grants from the Deutsche Forschungsgemeinschaft (Wo 148/16 and SFB 46).
We thank Mr. J.Zimmer for excellent technical assistance. We are greatly indebted to Prof. H. Fischer and Prof. B. Hess for stimulating discussions, and to Prof. U. Wolf and Prof. F. Vogel for constant support and encouragement.

\section{References}

Amacher, D. E., Elliott, J., A., Lieberman, M. W.: Differences in removal of acetylaminofluorene and pyrimidine dimers from the DNA of cultured mammalian cells. Proc. Natl. Acad. Sci USA 74, 1553-1557 (1977)

Berliner, J., Santos Mello, R., Norman, A.: Chromosomal localization of UV-induced unscheduled DNA synthesis. Radiat. Res. 68, 509-513 (1976)

Cleaver, J. E.: Repair processes for photochemical damage in mammalian cells. In: Advances in radiation biology, Vol.4, Lett, J. T., Adler, H., Zelle, M. (eds.), pp. 1-75. New York: Academic Press 1974

Cleaver, J. E., Trosko, J. E.: DNA degradation products from mammalian cells irradiated with ultraviolet light. Int. J. Radiat. Biol. 15, 411-424 (1969)

Cleaver, J. E., Thomas, G. H., Trosko, J. E., Lett, J. T.: Excision repair (dimer excision, strand breakage and repair replication) in primary cultures of eukaryotic (bovine) cells. Exp. Cell Res. 74, 67-80 (1972)

Comings, D. E.: The rationale of an ordered arrangement of chromatin in the interphase nucleus. Am. J. Hum. Genet. 20, 440-460 (1968)

Comings, D. E.: Arrangement of chromatin in the nucleus. Hum. genet. (in press, 1979)

Cornelis, J. J., Rommelaere, J., Urbain, J., Errera, M.: A sensitive method for measuring pyrimidine dimers in situ. Photochem. Photobiol. 26, 241-246 (1977)

Cremer, C., Zorn, C., Cremer, T.: An ultraviolet laser microbeam for $257 \mathrm{~nm}$. Microsc. Acta 75, 331-337 (1974) 
Cremer, C., Cremer, T., Zorn, C., Schoeller, L.: Effects of laser UV-microirradiation $(\lambda=2573 \AA)$ on proliferation of Chinese hamster cells. Radiat. Res. 66, 106-121 (1976)

Cremer, C., Cremer, T., Zorn, C., Cioreanu, V.: Partial UVirradiation of Chinese hamster cell nuclei and detection of unscheduled DNA synthesis in interphase and metaphase. A tool to investigate the arrangement of interphase chromosomes in mammalian cells. Hoppe Seylers Z. Physiol. Chem. $360,244-245$ (1979)

Cremer, T., Cremer, C., Zimmer, J., Zorn, C.: UV-microirradiation of Chinese hamster cells and posttreatment with caffeine: Indication for clastogenic effects remote from the irradiation site. In: DNA repair and late effects, Riklis, E., Slor, H., Altmann, H. (eds.), (in press, 1979)

Fukuda, M., Nakanishi, K., Mukainaka, T., Shima, A., Fujita, S.: Combination of Feulgen nuclear reaction with immunofluorescent staining for photoproducts of DNA after UVirradiation. Acta Histochem. Cytochem. 9, 180-192 (1976)

Inoue, M., Takebe, H.: DNA repair capacity and rate of excision repair in UV-irradiated mammalian cells. Jpn. J. Genet. 58, 285-295 (1978)

Johnson, R. T., Sperling, K.: Pattern of ultra-violet-light-induced repair in metaphase and interphase chromosomes. Int. $\mathbf{J}$. Radiat. Biol. 34, 575-582 (1978)

Levine, L., Seaman, E., Hammerschlag, E., Van Vunakis, H.: antibodies to photoproducts of deoxyribonucleic acids irradiated with ultraviolet light. Science 153, 1666-1667 (1966)
Lucas, C. J.: Immunological demonstration of the disappearance of pyrimidine dimers from nuclei of cultured human cells. Exp. Cell Res. 74, 480-486 (1972)

Moreno, G.: Effects of ultraviolet micro-irradiation on different parts of the cell: II. Cytological observations and unscheduled DNA synthesis after partial nuclear irradiation. Exp. Cell Res. 65, 129-139 (1971)

Schreck, R. R., Erlanger, B. F., Miller, O. J.: The use of antinucleoside antibodies to probe the organisation of chromosomes denatured by ultraviolet irradiation. Exp. Cell Res. 88, 31-39 (1974)

Stack, S. M., Brown, D. B., Dewey, W. C.: Visualization of interphase chromosomes. J. Cell Sci. 26, 281-299 (1977)

Vogel, F., Schroeder, T. M.: The internal order of the interphase nucleus. Humangenetik 25, 265-297 (1974)

Zorn, C., Cremer, T., Cremer, C., Zimmer, J.: Laser UV-microirradiation of interphase nuclei and posttreatment with caffeine. A new approach to establish the arrangement of interphase chromosomes. Hum. Genet. 35, 83-89 (1976)

Zorn, C., Cremer, C., Cremer, T., Zimmer, J.: Unscheduled DNA synthesis after partial UV irradiation of the cell nucleus. Distribution in interphase and metaphase. Exp. Cell Res. 124, 111-120 (1979)

Received September 20 / Revised December 14, 1979 